\title{
A Comparison of Attitudes Towards Risk Among Business Managers *
}

\author{
by Gordon C. A. Dickson **
}

\section{Introduction}

The business person is regarded by many as an example of someone confronted with risky choices. Their behaviour in such situations has been the subject of much study over the years both in attempting to describe past and prescribe future action.

The influence of attitude towards risk was the subject of examination by Grayson [1960], Green [1963] and Cramer and Smith [1963] when they derived utility functions for business executives. These early studies failed, however, to differentiate between those choices holding out the prospect of gain and those only holding out the chance of loss and Williams [1966] showed that people's preferences in these two differing situations were not the same.

Insurance decision making lent itself particularly well to the comparison of risky behaviour in loss and gain situations but much of the work in this area such as that by Murray [1971], Neter and Williams [1971] and Schoemaker [1976] was concerned with describing behaviour by means of a utility function.

Later work by Slovic et al. [1977], while still concerned with deriving a theory to explain risky behaviour by means of a utility function, did begin to analyse the choice itself by manipulating the probabilities and payoffs. Hershey and Schoemaker [1980] although relating the findings of their experiments concerning risk taking in the domain of losses with utility theory do make the point that aversion to risk in insurance decisions is not the same as risk aversion in gambling choices.

While these studies are centered mainly on the use of utility theory as a means by which risky behaviour can be explained or prescribed they do produce interesting facts relating to the underlying attitude towards risk held by many subjects. They are limited however by the frequent use of students as subjects for experiments and by the need to design experiments which allow for comparison of results with those derived by use of a utility function.

* Paper presented at the Eighth Seminar of the European Group of Risk and Insurance Economists, University of Cologne, September 1981.

** Senior Lecturer in Insurance and Risk Management, Glasgow College of Technology. 
This paper presents the findings of experiments which overcome both of these limitations and introduce a new dimension to the study of attitude towards risk in business situations. The studies reported so far have exposed a number of subjects to different sets of questions and have monitored their behaviour recording and commenting on any differences which arose. This present study is prompted by the hypothesis that business managers from different management functions will exhibit quite different attitudes towards risk when exposed to the same set of problems.

Continuing the insurance theme this study uses as its two groups of subjects a number of risk managers and a number of managers from other management areas. The risk manager is the person concerned, among other things, with the management of a company's insurance programme whether this involves the purchase of insurance or the organisation of a self insurance fund. They are therefore, as a group, continually confronted with problems holding out the chance of loss while concerned rarely with those occasions where some profit may result. The non-risk managers on the other hand are involved in work where profit or degree of profit is the attribute by which their effectiveness is measured and rarely will be concerned with decisions where only a loss or break even position is in prospect.

\section{Methodology}

\subsection{Sample selection}

The nature of the problem being examined required the use of practising managers. While this avoids problems associated with having non-managers, for example college students assume the role of managers, it does involve certain other difficulties. Assuming that a sufficient number of managers can be found, that they are willing to participate in the study, that their geographical location is not a problem there remains one final problem. How can managers be motivated to tackle the various experiments conscientiously? Mac Crimmon [1965] appealed to managers on academic grounds. Dickson [1978] provided an incentive by offering a bottle of whisky to certain subjects in exchange for points gained in the experiments. Unlike college students, managers will not be motivated by the possibility of course credits or the offer of a small fee.

No attempt was made to select subjects on a random basis as those who were approached were risk managers who had previously assisted the author. Each risk managers who agreed to participate was asked to obtain the assistance of one other non-risk manager from within their company. No conclusions will be drawn therefore about a wider population of managers and all interpretations of the results will be restricted to conclusions relating to those who participated.

\subsection{Measurement device}

As business men were being used as subjects it was decided to measure attitude to risk as evidenced in decision making problems as opposed to utilising one of the available attitudinal scales. To measure attitude to risk by monitoring actual decision 
making behaviour while not impossible, see Clarkson's [1962] classic study of the investment manager, would involve lengthy sessions with each subject. An alternative is to create a decision problem where the manager still stands to win or lose and then monitor behaviour. As the work of Suppes and Walsh [1962], Tversky [1967] and Dolbear [1963] shows, the pay-offs are necessarily restricted by the finance available to the researcher. This creates an unrealistic situation when contemplating the decision making behaviour of managers. The amounts of money used as pay-offs would have to be extremely large to be of any meaning to the business manager and even then may be far less than he or she was concerned with as a corporate decision maker.

In this study a number of hypothetical decision problems were created all of which should have been familiar to the subjects. Realistic business values were used and the decision incorporated in a story line to avoid the tendency to view the problem as a lottery and not a business decision.

One dilemma still remains in that we do not know for certain that the decision maker will act as he or she said they would in the real world. What can be said is that prior to making a decision one always considers the alternatives as hypothetical and presumably base a final choice on these considerations.

The decision problems were contained in a questionnaire which was mailed to each manager who had previously agreed to participate.

Each problem was of the same basic form :

$$
£ z=p £ x+(1-p) £ y .
$$

All the problems involved the manager in providing the value $z$ where there was a $p$ probability of $£ x$ and a $(1-p)$ probability of $£ y$. In each problem the probability of $p$ was .5 and one of the outcomes $x$ or $y$ was zero. Twenty-four problems were contained in the questionnaire with twelve involving a potential gain and twelve a potential loss. The example of Swalm [1966] was followed in using a probability of .5 . What was being tested was attitude towards risk and it was not thought that any purpose would be served by varying the probabilities.

In those questions involving a possible loss the subject was asked to provide the value of $z$ that represented the maximum amount he or she would pay to avoid taking the chancy alternative. In problems involving possible gains the value of $z$ was to represent the minimum a subject would accept below which he or she would prefer to take a chance on possibly gaining the amount shown in the problem.

This particular form of questioning was considered to be more realistic for business managers than one which asked for an indifference value.

An example of the decision problems used is a follows :

"you have been given the chance to make a bulk purchase of iron ore from abroad but you are not sure that an import licence would be granted. Unfortunately you must decide whether or not to buy the ore before you know the outcome of the government's deliberations over your import licence.

A friend in the relevant government department has told you there is a $50 / 50$ chance of getting the licence. If you get the licence the profit from selling in this country would be $£ 50,000$. If you fail to get the licence you would break even. 
An alternative course of action is to spend the money on buying finished metal sheets in this country which would be more expensive but will yield a definite profit.

What is the lowest definite profit you would accept rather than make the bulk purchase with the chances involved in doing that?"

\subsection{Scoring}

It was decided to score each subject according to the extent to which their $z$ value deviated from the expected monetary value (EMV) in each question.

With an EMV of $+£ 2,000$ any $z$ value greater than that would indicate a risk taker and any value less than $£ 2,000$ would show risk aversion. In other words faced with an EMV of $+£ 2,000$ the risk averter would prefer a smaller amount for certain rather than run any risk while the risk taker would always take the chance until offered a certainty equivalent which was much higher than the EMV of the chancy alternative. Similar comments can be made about negative EMVs.

Two problems arise. The first is that the signs will be different according to a positive or negative $z$ value. This was resolved by allowing the sign to indicate risk aversion or risk taking rather than losses or gains of actual amounts of money. With an EMV of $+£ 2,000$ and a subject selects a $z$ value of $£ 1,800$ this would be the action of a risk averter and the deviation from the EMV would be shown as $-£ 200$. For an EMV of $-£ 2,000$ and $z$ value of $-£ 1,700$ the deviation would be shown as $+£ 300$ indicating risk taking tendencies i.e., a person only willing to pay $£ 1,700$ to avoid a chance of loss where the EMV of that chance alternative is $-£ 2.000$.

The second problem is in the use of $z$ values in absolute money terms. The following set of figures illustrates the problem. $S_{1}$ and $S_{2}$ represent two subjects and $Q_{1}$ and $Q_{2}$ represent two different questions (see Figure 1 ).

Figure 1 : Comparison of scores used to measure risk taking attitude

\begin{tabular}{|c|c|c|}
\hline & $S_{1}$ & $S_{2}$ \\
\hline$Q_{1}$ & $\begin{array}{c}E M V+2200 \\
Z+2000 \\
(-200) \\
{[-.09]}\end{array}$ & $\begin{array}{c}E M V+2200 \\
Z+2500 \\
(+300) \\
{[+.14]}\end{array}$ \\
\hline$Q_{2}$ & $\begin{array}{c}E M V-230 \\
Z-200 \\
(+30) \\
{[+.13]}\end{array}$ & $\begin{array}{c}E M V-230 \\
Z-300 \\
(-70) \\
{[-.30]}\end{array}$ \\
\hline
\end{tabular}


The deviations, in absolute terms, are displayed in brackets directly beneath the $z$ values. When these are summed, subject $S_{1}$ has a score of -170 and $S_{2}$ of +230 . On this basis $S_{1}$ is an averter and $S_{2}$ a taker. By using the deviation on its own we have ignored the important relationship between it and the EMV. By expressing the deviation as a fraction of the EMV, the figures shown in the squared brackets, the position reverses and $S_{1}$ now becomes the risk taker and $S_{2}$ the averter. This is a more appealing result when the extent to which each subject deviated from the EMV, in relation to the size of the EMV itself, is studied.

A formula can be presented to represent what has been done :

$$
\frac{Z-E M V}{|E M V|}
$$

Where $z$ is the value chosen by the subject, EMV is the expected monetary value and |EMV | is the modulus EMV. It is necessary to use modulus EMV in order to preserve the sign of the numerator. It is this sign, positive or negative, which is important and must be preserved.

The score for each subject was calculated by taking the means of the scores over the twenty-four decision problems attempted.

Risk taking attitude is defined therefore for the purposes of this study as the mean of the deviations of actual choices from expected monetary values, expressed as a fraction of the absolute value of the expected monetary value, over a number of decision problems.

It is emphasised that as yet, it is not suggested one subject is a risk taker and another a risk averter but only that in relation to all other subjects each has shown him or herself to be different.

\section{Results}

Of the fifty-one questionnaires sent, twenty-nine were returned representing responses from fifteen risk managers and fourteen non-risk managers. Twenty-five respondents had working experience in excess of ten years with seventeen having more than twenty years working experience.

The scores for all subject are shown in Table 1 according to management type.

The risk managers appeared considerably more risk averse than non-risk managers. This is evidenced both by the means of their respective scores and the mean ranks. A Mann-Whitney U Test produced a U Statistic of 58 which has an associated two tailed probability of 0.040 . There was a statistically significant difference between the risk taking behaviour of each group of managers.

Further tests were then carried out to trace the source of this difference.

A Wilcoxon matched pairs test was employed to test for any significant difference over all subjects in their attitude when faced with a possible gain or loss. The decision problems were divided equally between those holding out a gain and those holding out a loss. While the mean score for all subjects in decisions involving gains was 
Table 1 : Risk taking attitude scores and ranks by management type

\begin{tabular}{|ccccc|}
\hline & \multicolumn{2}{c}{ Risk Managers } & \multicolumn{2}{c|}{ Non Risk Managers } \\
& Rank & Score & Rank & Score \\
& 2 & -0.537 & 1 & -1.029 \\
& 3 & -0.464 & 4.5 & -0.451 \\
& 4.5 & -0.451 & 10 & -0.209 \\
& 6 & -0.410 & 13 & -0.181 \\
& 7 & -0.333 & 15 & -0.147 \\
& 8 & -0.235 & 16 & -0.102 \\
& 9 & -0.215 & 20 & -0.053 \\
& 11 & -0.201 & 22.5 & -0.040 \\
& 12 & -0.186 & 22.5 & -0.040 \\
& 14 & -0.148 & 24 & -0.014 \\
& 17 & -0.065 & 25 & -0.013 \\
& 18 & -0.059 & 26 & -0.006 \\
& 19 & -0.055 & 28 & +0.174 \\
& 21 & -0.043 & 29 & +0.292 \\
Sums & 27 & +0.032 & & -1.819 \\
\cline { 2 - 5 } Means & 178.5 & -3.370 & 256.5 & -0.130 \\
\hline
\end{tabular}

-0.093 compared to a corresponding score of -0.266 for losses there was insufficient evidence to suggest any significant difference.

The Wilcoxon Test statistic, $T$, is approximately normally distributed for sample sizes larger than twenty-five and in this case $z$ value of -1.546 was produced which has an associated two tailed probability of 0.122 . The standard deviation of scores in loss producing problems, 0.497 , was three times higher than the corresponding figure for decisions holding out a possible profit.

The scores for both management groups over loss producing decisions were calculated and the results are in Table 2.

Table 2 :

Risk taking attitude scores in loss making decisions related to management type

\begin{tabular}{|cccc|}
\hline $\begin{array}{c}\text { Management } \\
\text { Type }\end{array}$ & $\begin{array}{c}\text { Number of } \\
\text { Subjects }\end{array}$ & Mean & Standard \\
Risk Managers & 15 & -0.3516 & Deviations \\
Non Risk Managers & 14 & -0.1727 & 0.354 \\
\end{tabular}

It was hypothesised that the risk managers familiarity with risky situations would lead them, as a group, to be more risk averse and a Mann-Whitney $U$ Test produced a U Statistic of 57 which has an associated one-tailed probability of 0.018 . 
As a comparison to the results shown in Table 2 a further test was carried out on those decisions holding out a possible gain. The results are shown in Table 3 from which it can be seen that there was very little difference between the scores for each management group. No significant difference was detected.

Table 3:

Risk taking attitude scores in profit making decisions related to management type

\begin{tabular}{|cccc|}
\hline $\begin{array}{c}\text { Management } \\
\text { Type }\end{array}$ & Number of & Mean & Standard \\
Subjects & Scores & Deviations \\
Risk Managers & 15 & -0.0975 & 0.144 \\
Non Risk Managers & 14 & -0.0874 & 0.184 \\
\hline
\end{tabular}

\section{Concluding comments}

The subjects in this study were in two groups, fifteen risk managers and fourteen managers performing some other management function not related to risk management. The subjects were mature managers all of whom had considerable working experience.

A significant difference in attitude to risk was detected between each group when they responded to a series of decision problems. The source of this difference was found to be in those decisions holding out a prospect of loss. In such decisions the risk managers were considerably more risk averse than their colleagues who in addition to being less risk averse also evidenced a lack of homogeneity as a group in their attitudes. There was a high degree of variation in score for non-risk managers around a mean score that was almost identical to the overall mean for all subjects for all questions. The fact that losses were involved did not seem to have any real effect on their mean risk taking attitude although the standard deviation of their scores was higher than the corresponding figure for all subjects over all questions.

The group of risk managers while being much more risk averse over losses than their colleagues showed little or no difference in attitude when confronted with decisions holding out the prospect of profit.

A number of points can be made :

a) Familiarity with loss would seem to lead to respect rather than contempt for the loss. This may not have an immediate intuitive appeal as many may consider that exposure to loss-producing events and the chance of loss over a continual period of time could lead a person to be increasingly less cautious. This does not seem to have been the case for the subjects in this study.

b) The experience of the non-risk managers will have been in the area of profit and degrees of profit. They may view a lower profit then expected as a loss but this is considerably different from these situations where only a loss is possible. This unfamiliarity with losses may have led them to conclude that the loss will really not happen to them. In other words they are prepared to take the chance that they will escape free of loss rather than experience a smaller but definite one. This is a 
common enough attitude among the public at large and may well prevail among corporate managers to some extent.

c) A further explanation of the non-risk managers' less risk averse behaviour could be the nature of their formal education. It will have been centred on profit maximisation and their contact with risk will most likely have been in the context of capital budgeting and investment appraisal where almost all the recognised techniques are concerned with profit or degrees of profit.

d) It is interesting that while the risk managers were able to adjust to the profit making problem, and display as a group a risk taking score very similar to that of the non-risk managers, a transition by these non-risk managers to loss producing events did not produce the same effect. This may imply that subjects are familiar with the profit producing event if not at a corporate level certainly at least at a private level and can respond accordingly. The loss producing event however has a certain unique character which results in people responding in a wide variety of ways, unless they have been trained and are to some extent confident in a loss producing situation.

e) To say that the risk managers did exercise a greater degree of risk aversion is not to suggest that they made the "best" decisions. It is a comment only on a difference in attitude as displayed in decision problems. It could be that the risk managers were exercising a level of aversion that was unhealthy from the point of view of their employer.

\section{REFERENCES}

CLARKSON, G.P.E. [1962]: Portfolio Selection: A Simulation of Trust Investment, Prentice-Hall, Englewood Cliffs (New Jersey).

CRAMER, R. M., and SMITH, B.E. [1963] : " Decision models for the selection of research projects ", Engineering Economist, 9, 1-20.

DICKSON, J.W. [1978] : "Subjective risk and choice as related to the transitivity condition", Psychological Reports, 42, 723-726.

DOLBEAR, F.T. [1963] : “Individual choice under uncertainty", Yale Economic Review, 418-469.

GRAYSON, C. J. [1960] : “Decisions under uncertainty : drilling decisions by oil and gas operators ", Division of Research, Harvard Business School, Boston (Mass.).

GREEN, P.E. [1963] : “Risk attitudes and chemical investment decisions", Chemical Engineering Progress, 59, 35-40.

HERSHEY, J. C., and SCHOEMAKER, P. J. M. [1980] : "Risk taking and problem context in the domain of losses: An expected utility analysis", Journal of Risk and Insurance, 47 (March 1980), 112-132.

MAC CRIMMON, K. [1965] : An Experimental Study of the Decision Making Behaviour of Business Executives, unpublished Doctoral Thesis, University of California, Los Angeles.

MURRAY, M. L. [1971] : “A deductible selection model : Development and application", Journal of Risk and Insurance, 38 (September 1971), 423-436.

NETER, J., and WILLIAMS, C. A. [1971] : "Acceptability of three normative methods in insurance decision making ", Journal of Risk and Insurance, 38 (September 1971), 385-408. 
SCHOEMAKER, P.J.M. [1976] : Experimental Studies on Individual Decision Making Under Risk, unpublished doctoral Thesis, University of Pennsylvania.

SLOVIC, P., et al. [1977] : "Preference for insuring against probable small losses", Journal of Risk and Insurance, 44 (June 1977), 237-258.

SUPPES, P., and WALSH, K. [1967] : " A non-linear model for the experimental measure of utility ", Behavioural Science, 4, 204-211.

SWALM, R. O. [1966] : "Utility theory - Insights into risk taking", Harvard Business Review, 44, 123-136.

TVERSKY, A. [1967]: “Additivity, utility and subjective probability", Journal of Mathematical Psychology, 4, 175-201.

WILLIAMS, C. A. [1966] : "Attitudes towards speculative risk as an indicator of attitudes towards pure risk", Journal of Risk and Insurance, 33 (December 1966), 577-586. 